\title{
A Conserved Odorant Receptor Detects the Same 1-Indanone Analogs in a Tortricid and a Noctuid Moth
}

\begin{abstract}
Francisco Gonzalez ${ }^{1 *}$, Jonas M. Bengtsson ${ }^{2 \dagger}$, William B. Walker ${ }^{1}$, Maria F. R. Sousa ${ }^{1}$, Alberto M. Cattaneo ${ }^{2}$, Nicolas Montagné ${ }^{3}$, Arthur de Fouchier ${ }^{3}$, Gianfranco Anfora ${ }^{2}$, Emmanuelle Jacquin-Joly ${ }^{4}$, Peter Witzgall ${ }^{1}$, Rickard Ignell ${ }^{1 \neq}$ and Marie Bengtsson ${ }^{1 \neq}$
\end{abstract}

\begin{abstract}
${ }^{1}$ Chemical Ecology Unit, Department of Plant Protection Biology, Swedish University of Agricultural Sciences, Alnarp, Sweden, ${ }^{2}$ Chemical Ecology, Department of Agrosystems, Sustainability and Bioresources, Fondazione Edmund Mach, San Michele all'Adige, Italy, ${ }^{3}$ Chemoreception and adaptation, Institute of Ecology and Environmental Sciences (IEES), Sorbonne Universités, UPMC Université Paris 6, Paris, France, ${ }^{4}$ Department of Sensory Ecology, Institut National de la Recherche Agronomique, Versailles, France
\end{abstract}

Odorant receptors (ORs) interface animals with airborne chemical signals. They are under strong selection pressure and are therefore highly divergent in different taxa. Yet, some OR orthologs are highly conserved. These ORs may be tuned to odorants of broad importance, across species boundaries. Two widely distributed lepidopteran herbivores, codling moth Cydia pomonella (Tortricidae) feeding in apples and pears, and the African cotton leafworm Spodoptera littoralis (Noctuidae), a moth feeding on foliage of a wide range of herbaceous plants, both express a receptor ortholog, OR19, which shares 58\% amino acid identity and 69\% amino acid similarity. Following heterologous expression in the empty neuron system of Drosophila melanogaster, we show by single sensillum recordings that CpomOR19 and SlitOR19 show similar affinity to several substituted indanes. Tests with a series of compounds structurally related to 1-indanone show that 2-methyl-1-indanone, 2-ethyl-1-indanone, 3-methyl-1-indanone, and 1-indanone elicit a strong response from both ORs. A keto group in position 1 is essential for biological activity and so are both rings of the indane skeleton. However, there is an important difference in steric complementary of the indane rings and the receptor. Methyl substituents on the benzene ring largely suppressed the response. On the other hand, alkyl substituents at position 2 and 3 of the five-membered ring increased the response indicating a higher complementarity with the receptor cavity, in both CpomOR19 and SlitOR19. Our results demonstrate a conserved function of an odorant receptor in two moths that are phylogenetically and ecologically distant. It is conceivable that a conserved OR is tuned to signals that are relevant for both species, although their ecological roles are yet unknown. Our finding demonstrates that functional characterization of ORs leads to the discovery of novel semiochemicals that have not yet been found through chemical analysis of odorants from insects and their associated host plants.

Keywords: Cydia pomonella, Spodoptera littoralis, olfaction, olfactory receptor, 1-indanone, orthologous genes, structure activity relationships, functional characterization 


\section{INTRODUCTION}

Perception of olfactory cues plays a fundamental role in insect life, and the olfactory system has evolved through adaptations to new environments, host, plant, and mate-finding signals (Bergstrom, 2008; Smadja and Butlin, 2009; Hansson and Stensmyr, 2011). Several studies have shown that the family of odorant receptor (OR) genes, which encode for proteins that detect and discriminate odorants, is highly divergent among insect taxa and even among closely related species (JacquinJoly and Merlin, 2004; Su et al., 2009; Engsontia et al., 2014; Depetris-Chauvin et al., 2015). This suggests that olfactory systems have evolved rapidly to enable perception of relevant odor signals. Selection drives the evolution of genes that facilitate host and mate finding, whereas behaviorally redundant OR genes are no longer expressed (Sánchez-Gracia et al., 2009; Hansson and Stensmyr, 2011; Suh et al., 2014; Andersson et al., 2015). Consequently, the insect OR repertoire is expected to be tuned to odor cues of ecological relevance, as indicated in the functional comparison between the OR repertoire of the vinegar fly, Drosophila melanogaster, and the malaria mosquito Anopheles gambiae, which shows little overlap (Hill et al., 2002; Carey et al., 2010; Suh et al., 2014; Karner et al., 2015). Orthologous ORs are of particular interest since may be tuned to odorants that are behaviorally and ecologically relevant across species (Bohbot et al., 2011).

Insect ORs identified so far generally show a low level of sequence conservation between species, ranging from 20 to $40 \%$ amino acid identity (Rützler and Zwiebel, 2005; Bohbot et al., 2007; Martin et al., 2011; Engsontia et al., 2014). A striking exception is the OR co-receptor, ORco, which shares 60$90 \%$ amino acid identity across different insect orders (Krieger et al., 2003; Larsson et al., 2004). A plausible reason for this conservation may lie in its function: ORco is an obligate coreceptor that forms a complex with ligand-selective ORs and is required for trafficking to olfactory neuron dendrites in all insects (Larsson et al., 2004; Jones et al., 2011). Apart from ORco, conserved ligand-selective ORs have been identified in closely related species. The OR2/OR10 clade of the mosquitoes Aedes aegypti and An. gambiae share $69 \%$ of amino acid identity and both respond strongly to indole, an important host signal for both species (Bohbot et al., 2011). Within Lepidoptera, several examples of conserved function for orthologous receptors have been reported, especially within the pheromone receptor family (de Fouchier et al., 2014; Jiang et al., 2014). There are clusters of ORs, however, that share high amino acid identity across species but whose function has not yet been elucidated; for example, OR18, a highly conserved receptor in six noctuid species, with an average of $88 \%$ amino acid identity (Brigaud et al., 2009).

A number of lepidopteran OR gene repertoires have been described, following genome and transcriptome sequencing (Jordan et al., 2009; Grosse-Wilde et al., 2011; Montagné et al., 2012, 2014; Cao et al., 2014; Gu et al., 2014; Liu et al., 2014; Corcoran et al., 2015; Yang et al., 2015; Zhang et al., 2015a,b). In our own transcriptome sequence analyses of the antennae of the codling moth (Cydia pomonella: Tortricidae; Bengtsson et al., 2012) and the cotton leafworm (Spodoptera littoralis:
Noctuidae; Legeai et al., 2011; Jacquin-Joly et al., 2012; Poivet et al., 2013) we have identified one OR (OR19) with relatively high sequence similarity in both species. In S. littoralis, SlitOR19 was shown to be narrowly tuned to 1-indanone (de Fouchier et al, unpublished). We have compared the responses of SlitOR19 and its homolog CpomOR19 to 1-indanone, and its analogs, showing a similar response spectrum for these receptor orthologs in the codling moth and the African cotton leafworm. A qualitative structure-activity study of these receptors leads toward a better comprehension of the effect of amino acid sequence differences on OR tuning.

\section{MATERIALS AND METHODS}

\section{Phylogenetic and Sequence Analysis}

The previously described CpomOR19 amino acid sequence (Bengtsson et al., 2012) was used as a query in BLASTp search on the NCBI database (http://www.ncbi.nlm.nih.gov/BLAST/Blast. cgi). Among hits, putative ORs belonged to lepidopteran species only (C. pomonella, S. littoralis, Bombyx mori, Heliothis virescens, Helicoverpa armigera, Helicoverpa assulta, Manduca sexta, and Danaus plexippus). Sequences of the putative ORs retrieved were aligned with MAFFT, using the FFT-NS-2 algorithm with default parameters. A maximum likelihood tree was constructed with MEGA6 using the JTT $+\mathrm{F}$ algorithm with a bootstrap consensus inferred from 1000 replicates and Poisson correction of distances (Tamura et al., 2013).

The membrane topologies and transmembrane domains of CpomOR19 and SlitOR19 were predicted with five different prediction models-TMHMM (https://www.cbs.dtu.dk/services/ TMHMM/), METSAM-SVM (http://bioinf.cs.ucl.ac.uk/ psipred/), TOPCONS (http://topcons.cbr.su.se/), RHYTHM (http://proteinformatics.charite.de/rhythm/), and TMPRED (http://www.ch.embnet.org/software/TMPRED_form.html).

From these, we selected the model that best fitted the OR characteristic structure (seven-transmembrane domains and extracellular C-terminus) and illustrated it with Protter (Omasits et al., 2014).

\section{Heterologous Expression of Putative ORs in Drosophila melanogaster}

The complete open reading frames (ORFs) encoding CpomOR19 and SlitOR19, from start codon to stop codon, were amplified by PCR, (CpomOR19: forward primer $5^{\prime}$-ATGTTTAGTTAT GAAAATGAAGACAGC-3', reverse primer $5^{\prime}$-TCAAGTCAT TTCTTCAGTAGAGGT-3'; SlitOR19: forward primer $5^{\prime}$-ATG AAAAACCATTACATCTTGAA-3 ${ }^{\prime}$, reverse primer $5^{\prime}$-TTACGA AGTTTGCGCATAAAAC-3'), using antennal cDNA synthetized with the RT-for-PCR kit (Invitrogen) as a template. For cloning of OR19 homologs, total RNA was extracted from 100 dissected antennae of mixed male and female 2-3 day old adult moths of each species. For extractions Trizol reagent (Invitrogen) was used according to manufacturer's standard protocol. After extraction, total RNA was purified via spin column purification with the RNeasy Mini Kit (Qiagen) according to manufacturer's standard protocol. Total RNA was used as template for first 
strand cDNA synthesis with the RevertAid $\mathrm{H}$ minus Reverse Transcriptase kit, according to manufacturer's standard protocol. ORF sequence from start codon to stop codon of OR19 was PCR amplified from the cDNA. The purified PCR products were then cloned into the PCR8/GW/TOPO plasmid (Invitrogen), after which One Shot TOP10 cells were transformed (Invitrogen), and plated for overnight growth on Spectinomycin selective lysogeny broth (LB) growth plates. Colonies were assayed for the presence of the relevant insert in the correct orientation by PCR using either the forward gene specific primer (GSP) together with the M13 reverse primer, or the reverse GSP together with the M13 forward primer. Plasmids were purified by Miniprep (Qiagen), and then sequenced to confirm the presence and integrity of the OR inserts. The cassettes with the inserts were then transferred from the PCR8/GW/TOPO plasmid into the destination injection vector (pUASg-HA.attB) constructed by E. Furger and J. Bischof, kindly provided by the Basler group, Zürich (Bischof et al., 2007), using the Gateway LR Clonase II kit (Invitrogen). The destination vector with the correct insert (as confirmed by sequencing) was transformed into One Shot TOP10 cells (Invitrogen). Resultant colonies were cultured in $20 \mathrm{ml}$ of LB media with Ampicillin and purified by Midiprep (Qiagen); the integrity and orientation of the inserts was confirmed by sequencing. Transformant UAS-CpomOR19 and UAS-SlitOR19 lines were generated by BestGene (Chino Hills, CA, USA) and Fly Facility (Clermont-Ferrand, France), respectively, using the PhiC31 integrase system. Briefly, recombinant pUASg-HA.attBCpomOR19 and -SlitOR19 plasmids were injected into embryos of a $D$. melanogaster line containing an attP insertion site within the third chromosome (genotype y1 M\{vas-int.Dm\}ZH$2 \mathrm{~A} \mathrm{w}^{*} ; \mathrm{M}\{3 \mathrm{xP} 3-\mathrm{RFP} . \mathrm{attP}\} \mathrm{ZH}-86 \mathrm{Fb}$ ), leading to non-random integration; the transgenes were then crossed into the $\Delta$ halo mutant background. To drive expression of CpomOR19 and SlitOR19 in OSNs housed in the ab3 basiconic sensilla, the described transgenic lines were crossed with $\Delta$ halo; OR22a-Gal4 mutant D. melanogaster (Dobritsa et al., 2003; Hallem et al., 2004).

\section{Single Sensillum Recordings}

Flies expressing either CpomOR19 or SlitOR19 in the A neuron of ab3 basiconic sensilla were tested by single sensillum recordings (SSRs). Flies were restrained as described in Stensmyr et al. (2003). Briefly, flies were trapped inside $100 \mu l$ pipette tips with only the top half of the head protruding. A glass capillary was used to push the left antenna onto a piece of double-sided adhesive tape placed on a piece of glass. Both the pipette tip and the piece of glass with the antennae were mounted and fixed with dental wax on a microscope slide. Tungsten electrodes (diameter $0.12 \mathrm{~mm}$, Harvard Apparatus Ltd., Edenbridge, UK), were electrolytically sharpened with a saturated $\mathrm{KNO}_{3}$ solution, and used to penetrate the eye and the sensilla of the flies. The recording electrode (introduced at the base of the sensilla) was maneuvered with a DC-3K micromanipulator equipped with a PM-10 piezo translator (Märzhäuser Wetzler GmbH, Germany). The reference electrode was manually inserted through the eye. The signal from the olfactory sensory neurons (OSNs) was amplified 10 times with a probe (INR-02, Syntech, Hilversum, the Netherlands), digitally converted through an IDAC-4-USB (Syntech) interface, visualized and analyzed with the software Autospike v. 3.4 (Syntech).

During the recording sessions, a constant flow of $0.65 \mathrm{~m} / \mathrm{s}$ of charcoal-filtered and humidified air was delivered through a glass tube with the outlet $15 \mathrm{~mm}$ apart from the antenna. The panel of odorant stimuli was presented to the insect by blowing air through pipettes inserted in a lateral hole of the glass tube delivering the constant charcoal-filtered humidified air. The air puff was controlled with a stimulus controller (Syntech SFC-1/b) and consisted of a flow of $2.5 \mathrm{ml}$ of air during $0.5 \mathrm{~s}$.

\section{Synthetic Compounds and Odorant Stimuli}

To determine ligands detected by CpomOR19, initially a panel with a wide range of synthetic compounds was tested (Table 1). The list of compounds included general plant odors previously tested for deorphanization of SlitOR19 (de Fouchier et al, unpublished), codling moth pheromone components (Arn et al., 1985), and microbial odorants (Witzgall et al., 2012). Compounds were diluted in redistilled hexane (LabScan), acetone (SigmaAldrich), or paraffin oil (Merck) to a concentration of $10 \mu \mathrm{g} / \mu \mathrm{l}$. Stimuli were prepared by applying $10 \mu \mathrm{l}(100 \mu \mathrm{g})$ of the diluted test compounds to $1.5 \times 1 \mathrm{~cm}$ pieces of filter paper placed inside disposable glass Pasteur pipettes (VWR International, Stockholm, Sweden). Pipette tips were placed on the end of the Pasteur pipettes to decrease evaporation of compounds. Control pipettes with only solvent (hexane, acetone, and paraffin oil) were also prepared.

To investigate structural activity relationships between 1indanone and selected analogs, a second odorant panel was tested for flies expressing either CpomOR19 or SlitOR19 (Figure 1). Compounds eliciting significant response in comparison to the solvent were used for dose response experiments, the concentration of the test compounds ranged from $1 \mathrm{ng}$ to $100 \mu \mathrm{g}$ in decadic steps applied to the filter paper in the stimulus pipette. Comparisons between receptor-activating compounds were made after correction for differences in vapor pressure (Bengtsson et al., 1990).

Fresh filter papers were prepared before each recording session, and kept at $-18^{\circ} \mathrm{C}$ until the start of the recording session. Only complete recording sessions of the entire set of test stimuli were evaluated, and only one screening or dose response session was performed per individual fly and on a single sensillum.

SSR responses were quantified by counting the number of spikes for $500 \mathrm{~ms}$ starting from the onset of the response (as determined by the earliest response for the recording session), subtracting the number of spikes during $500 \mathrm{~ms}$ before response. Five whole-panel screenings for ligands of CpomOR19 were performed, screenings of the panel of structurally related compounds were done five times for CpomOR19 and SlitOR19. For dose response experiments, eight replicates were carried out at each dose for each receptor.

Responses of CpomOR19 and SlitOR19 to the panel of structurally related compounds and dose response experiments 
TABLE 1 | Responses of $D$. melanogaster flies expressing CpomOR19 to synthetic compounds tested at $100 \mu \mathrm{g}$ on filter paper.

\begin{tabular}{|c|c|c|c|c|}
\hline $\begin{array}{l}\text { Compound } \\
\text { class }\end{array}$ & Compound & $\begin{array}{l}\text { Chemical } \\
\text { purity (\%) }\end{array}$ & Source & $\begin{array}{c}\text { Spike } \\
\text { frequency }^{\mathrm{a}}\end{array}$ \\
\hline \multicolumn{5}{|c|}{ HYDROCARBONS } \\
\hline \multirow[t]{5}{*}{ Monoterpenes } & $\alpha$-Pinene & 98 & Aldrich & + \\
\hline & $\beta$-Pinene & 99 & Fluka & + \\
\hline & $\beta$-Myrcene & 95 & Fluka & \\
\hline & $\beta$-Ocimene & 90 & Safc & \\
\hline & 3-Carene & 95 & Aldrich & \\
\hline \multirow[t]{4}{*}{ Sesquiterpenes } & $\alpha$-farnesene & 99 & Bedoukian & \\
\hline & $\alpha$-Copaene & 98 & Bedoukian & \\
\hline & $\alpha$-Humulene & 98 & Aldrich & + \\
\hline & $\beta$-Caryophyllene & 98.5 & Aldrich & \\
\hline \multirow[t]{2}{*}{ Homoterpenes } & $\mathrm{TMTT}^{\mathrm{b}}$ & 98 & Aldrich & + \\
\hline & DMNTC,d & 95 & & \\
\hline \multicolumn{5}{|l|}{ ALCOHOLS } \\
\hline \multirow[t]{12}{*}{ Aliphatics } & 1-Hexanol & 98 & Aldrich & ++ \\
\hline & 1-Heptanol & 99 & Aldrich & \\
\hline & 1-Octanol & 99.5 & Aldrich & \\
\hline & 1-Nonanol & 99.5 & Aldrich & \\
\hline & 1-Tetradecanol & 99 & Fluka & + \\
\hline & (Z)-3-Hexenol & 98 & Aldrich & + \\
\hline & (E)-2-Hexenol & 96 & Aldrich & + \\
\hline & Butyl alcohol & 99.5 & Sigma & + \\
\hline & (E)-3-Hexen-1-ol & 97 & Aldrich & + \\
\hline & Codlemone $^{\mathrm{e}}$ & 98.6 & & \\
\hline & 1-Dodecanol & 98 & Fluka & + \\
\hline & (E)-9-Dodecenol & 99 & $\begin{array}{l}\text { Farchan } \\
\text { Labs Inc }\end{array}$ & + \\
\hline \multirow[t]{4}{*}{ Aromatics } & Thymol & 99.5 & Aldrich & \\
\hline & Carvacrol & 98 & Aldrich & + \\
\hline & Eugenol & 98 & Aldrich & \\
\hline & Estragol & 96 & Sigma & \\
\hline \multirow[t]{3}{*}{ Monoterpenes } & Geraniol & 98 & Aldrich & \\
\hline & Citronellol & 95 & Aldrich & \\
\hline & \pm Linalool & 97 & Aldrich & + \\
\hline \multirow[t]{2}{*}{ Sesquiterpenes } & $(E, E)$-Farnesol & 95 & Aldrich & + \\
\hline & \pm Nerolidol & 98 & Aldrich & + \\
\hline Diterpenes & Phytol & 99 & Aldrich & \\
\hline \multicolumn{5}{|l|}{ ALDEHYDES } \\
\hline \multirow[t]{3}{*}{ Aliphatics } & (E)-2-Hexenal & 98 & Aldrich & + \\
\hline & Nonanal & 95 & Aldrich & \\
\hline & Decanal & 99 & Aldrich & \\
\hline \multirow[t]{2}{*}{ Aromatics } & Phenyl acetaldehyde & 98 & Aldrich & \\
\hline & Benzaldehyde & 99.5 & Aldrich & \\
\hline \multicolumn{5}{|l|}{ ETHERS } \\
\hline Aromatics & Benzyl methyl ether & 98 & Aldrich & \\
\hline \multicolumn{5}{|l|}{ ESTERS } \\
\hline \multirow[t]{4}{*}{ Aliphatics } & (Z)-3-Hexenyl acetate & 98 & Aldrich & \\
\hline & Butyl butyrate & 99 & Aldrich & \\
\hline & Methyl hexanoate & 99 & Aldrich & + \\
\hline & Hexyl butyrate & 98 & Aldrich & \\
\hline
\end{tabular}

(Continued)
TABLE 1 | Continued

\begin{tabular}{|c|c|c|c|c|}
\hline $\begin{array}{l}\text { Compound } \\
\text { class }\end{array}$ & Compound & $\begin{array}{l}\text { Chemical } \\
\text { purity (\%) }\end{array}$ & Source & $\begin{array}{c}\text { Spike } \\
\text { frequency }^{2}\end{array}$ \\
\hline & Methyl jasmonate & 98 & Aldrich & \\
\hline & Propyl hexanoate & 99 & Aldrich & + \\
\hline & Pear ester & 98 & Aldrich & + \\
\hline & Isoamyl acetate & 95 & Aldrich & + \\
\hline & Isobutyl acetate & 99 & Aldrich & + \\
\hline & Codlemone acetate & 97 & Bedoukian & + \\
\hline & Hexyl propionate & 97 & Aldrich & + \\
\hline & Butyl acetate & 99 & Aldrich & + \\
\hline \multirow[t]{3}{*}{ Aromatics } & Methyl salicylate & 99 & Sigma & + \\
\hline & Methyl benzoate & 99 & Aldrich & + \\
\hline & 2-Phenylethyl acetate & 99 & Aldrich & \\
\hline \multicolumn{5}{|l|}{ KETONES } \\
\hline \multirow[t]{4}{*}{ Aliphatics } & Geranyl acetone & 96 & Aldrich & + \\
\hline & (Z)-Jasmone ${ }^{d}$ & 98 & & \\
\hline & 2-Heptanone & 98 & Aldrich & + \\
\hline & Sulcatone & 98 & Aldrich & + \\
\hline \multirow[t]{2}{*}{ Aromatics } & Acetophenone & 99 & Acros & + \\
\hline & 1-indanone & 99 & Aldrich & +++ \\
\hline \multicolumn{5}{|l|}{ ACIDS } \\
\hline Aliphatics & Acetic acid & 99 & Aldrich & \\
\hline \multicolumn{5}{|l|}{ OTHERS } \\
\hline & Indole & 99 & Aldrich & \\
\hline
\end{tabular}

a Spike frequency $(\mathrm{Hz})$ is used as measure of response strength: $1-10 \mathrm{~Hz}(+), 11-49 \mathrm{~Hz}$ $(++),>50 \mathrm{~Hz}(+++)$.

${ }^{b}(E, E)$ 4,8,12-trimethyltrideca-1,3,7,11-tetraene.

${ }^{c}(E)$-4,8-dimethyl-1,3,7-nonatriene.

${ }^{d}$ Gift from Prof. Wittko Francke.

${ }^{e}$ Gift from Prof. Heinrich Arn.

were compared with Two-way ANOVA with repeated measures, followed by LSD post-hoc test. All statistical analyses were performed using SPSS Version 19.0 (IBM Corp., Armonk, NY, USA).

\section{RESULTS}

\section{Phylogeny and Sequence Analysis}

Comparison of protein sequences of putative orthologs from different lepidopteran species showed that the receptors OR21 and OR22 of B. mori, along with OR19 of S. littoralis, $H$. virescens, and C. pomonella cluster within one group (Figure 2). Among these sequences, SlitOR19 shared the highest amino acid identity (58\%) with CpomOR19, while the others share $42-55 \%$ (Figure 3A). According to receptor topology prediction (OCTOPUS algorithm, TOPCONS), the main differences between the two sequences were observed in the putative extracellular C-terminus which SlitOR19 has a four residues shorter sequence, along with the addition of residues in two regions, one located in the fourth transmembrane domain $(\mathrm{M})$ and the other in the third intracellular loop (RPKSAP). However, most of the non-conservative point mutations correlated to substitutions in 

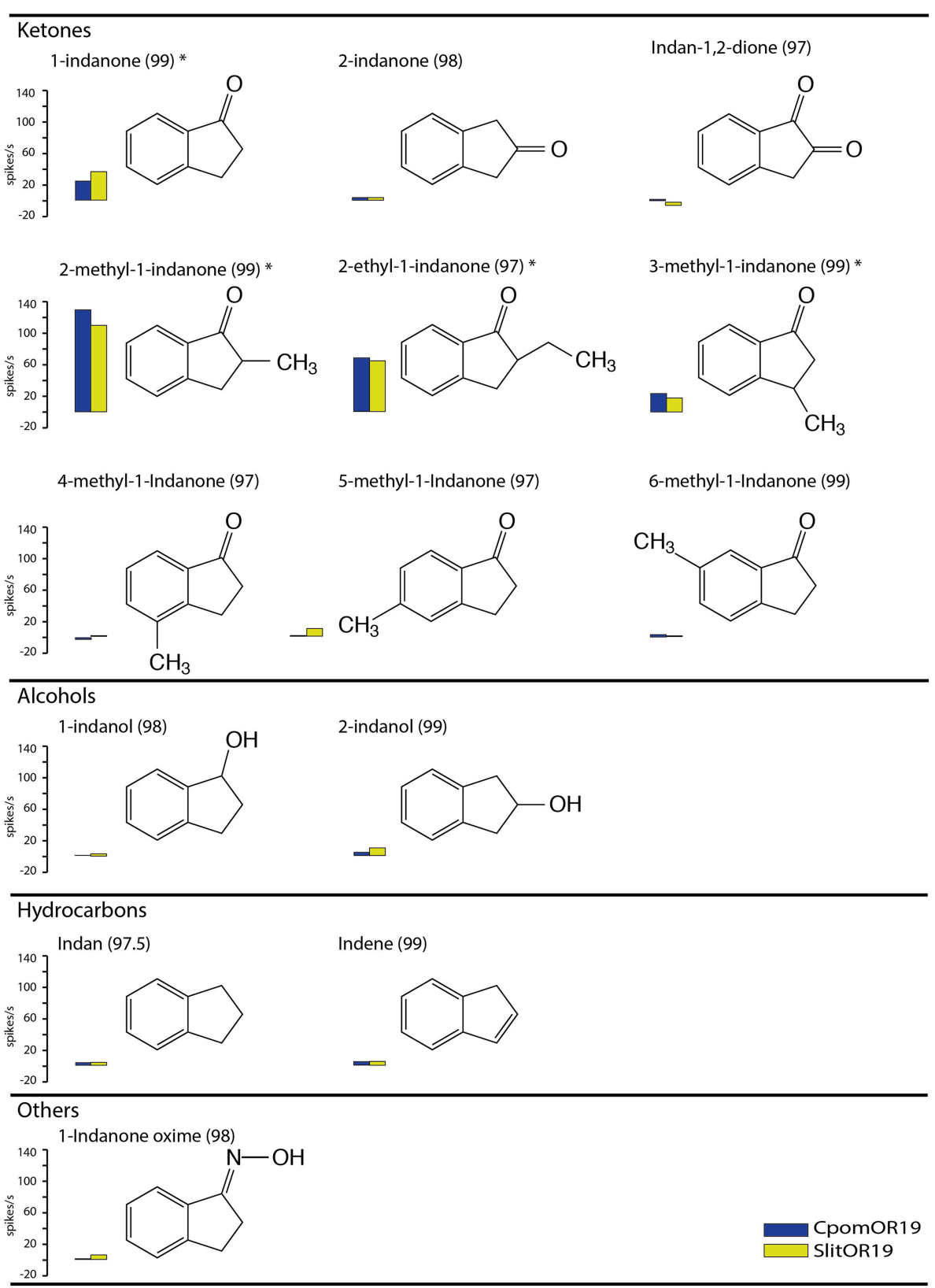

FIGURE 1 | Response profiles of CpomOR19 and SlitOR19 to 1-indanone and structurally related compounds at $100 \mu \mathrm{g}$ on filter paper. Asterisks denote significant differences between the response elicited by the indicated compound and the solvent at $P<0.05$ (Two-way ANOVA with repeated measures, LSD post-hoc test, $n=5$ ). Chemical purity is shown in brackets, compounds were purchased from Aldrich.

the first transmembrane region and in the cytoplasmic side (loop 2 ), while only a few mutations are predicted to be located on the extracellular side (Figure 3B).

\section{Selectivity of CpomOR19 toward Putative Ligands}

SSR recordings from ab3A OSN of D. melanogaster that expressed CpomOR19 showed that of 64 stimuli tested at the maximum dose of $100 \mu \mathrm{g}$ loaded on filter paper, only 1-indanone elicited a strong electrophysiological response $(>50 \mathrm{~Hz}$; Table 1, Supplementary Figure 1).

Effect of Chemical Structure on Specificity
and Sensitivity of CpomOR19 and SlitOR19 When tested at the maximum dose of $100 \mu \mathrm{g}$, the responses of CpomOR19 and SlitOR19 did not differ significantly between them for any of the indanone analogs tested. Besides 1-indanone, both ORs responded to three of the other 13 compounds tested. 




FIGURE 2 | Maximum-likelihood tree of the sequences of Cydia pomonella CpomOR19 and homologs from other lepidopteran species. The distance tree is calculated by MEGA6 based on sequence alignment using MAFFT. Branch support is shown for values above 60\%. C. pomonella (Cpom), B. mori (Bmor), S. littoralis (Slit), S. litura (Slitu), H. virescens (Hvir), D. plexippus (Dple), M. sexta (Msex), H. assulta (Hass), H. armigera (Harm).

The strongest responses were elicited by 2-methyl-1-indanone and 2-ethyl-1-indanone, followed by 1-indanone and 3-methyl1-indanone (Figure 1).

Dose-response experiments also revealed that both CpomOR19 and SlitOR19 had a lower threshold for 2-methyl-1indanone and 2-ethyl-1-indanone, reacting to lower amounts of these than to 1-indanone and 3-methyl-1-indanone (Figure 4). For 2-methyl-1-indanone, $1 \mu \mathrm{g}$ on the filter paper was sufficient to elicit a significant response in comparison to the solvent and with correction for differences in vapor pressure taken into account, 2-ethyl-indanone elicited above-threshold responses at quantities below $1 \mu \mathrm{g}$. The only significant discrepancy between the two receptors was observed in CpomOR19 that responded more strongly to 3-methyl-indanone than SlitOR19 at a dose of $10 \mu \mathrm{g}$.

\section{DISCUSSION}

Codling moth C. pomonella (Lepidoptera, Tortricidae) and African cotton leafworm S. littoralis (Lepidoptera, Noctuidae) share two orthologous ORs with conserved function, CpomOR19 and SlitOR19 (Figures 1, 2). Furthermore, SlitOR19 and
CpomOR19 are expressed in adults of both sexes of S. littoralis and C. pomonella (Bengtsson et al., 2012; Poivet et al., 2013). This is an intriguing finding: in addition to taxonomic position (Kristensen et al., 2007), the two species differ with respect to host plant and feeding habit. C. pomonella larvae mine in apple and pear fruit, or in walnuts, whereas $S$. littoralis feeds on the leaves of a very wide range of herbaceous plants (Salama et al., 1971; Bradley et al., 1979). The occurrence of receptors with conserved function and their similar expression patterns likely reflect a role of one or more substituted indanone compounds in the behavioral ecology of these two species.

\section{Structurally and Functionally Conserved ORs}

Sequence similarity is not a reliable indicator of OR function. However, our results show that the response profiles of CpomOR19 and SlitOR19, with 58\% amino acid identity, are virtually the same: both respond to 1-indanone and structurally related compounds (Figures 1, 3A). Similarly, pheromone receptors from heliothinae moths, HarmOR14b, HassOR16 and HvirOR6, with amino acid identities between 53 and 65\%, all responded to (Z)-9-tetradecenal (Jiang et al., 2014). In contrast, 
A

CpomoR19

slitoR19

CpomoR 19

SlitoR19

CpomoR 19

SlitoR19

CpOMOR19

slitoR19

CpomOR19

SlitoR19

CpOmOR19

SlitoR 19

CpomOR19

slitoR 19

B
MKNYF ILKNLCRK IYLVGAGDFWFEEGE ISKGKSLRYQFLCFVLFS IY IFMTVLEI IGVF MKNHY ILKTYCKRIFLIGSGNFWYKESE I GNDQSLLYRTYNAVLYF IYGFMT ILEIMAAT $* * *:: * * * . *:: *^{*}::^{*}: *: * *:: * * * *:: * * *:$ $* *: * * * * *: * * *: \ldots$

FGDMPKDERSDCTTFAVSHT IVLGKMFSVILNRKRVKELNRKLVE ICANHEDEHRVAENY MGDFPPDEKRDSVSFAVSHTIAMIKIFSVIANKSLIKKLNHKMVTVCERYEENTLMAEKY

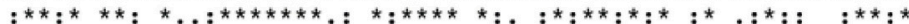

RIMK INIWAFAVSVYGSF IFFLFEGIRKMMSGSHF ITIVTYWPFYEDNSI IAVSFRFFTT KIMK INVLAYFVTVYASAFFFVFEGLRKMLTGSHFVTVVTYYPKFEDDSIGATSARVLAT

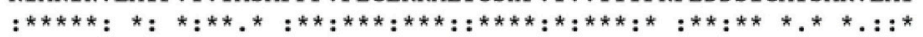

LVLAVMMAT-MICIDSFAMI ILIMYKYKF ITLRYYFEGLRERFDRNNYTGNEEYATELLH VILY ILMITMIMSVDSFTMIYLIMYKYKF ITLKOYFENLREEVSALNARREYDMAAEKMA

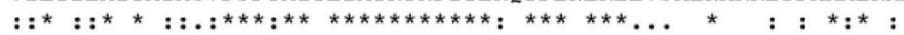

AGF IEGIVMHSNLTRLSKDIDRSVGTVLALQVCLSSGSAVSLLLQLALSKDLTVAAQLKI AGLVEG IQMHNTLLRLSGDIDKAFGTVMALQVCQSSGSAVSLLLQIALSDQLTFIASMKI $* *:: * * * * * . . * * * * * * *:: . * * *: * * * * * * * * * * * * * * *: * * * .: * * . * * .: * *$

IMFVIAVFFLLALFLCNAGE ITYQASLLSDS IFYCGWDASSM------RRDLRRLVLFSC IFFVVALFFLLGLFLCNAGE ITYQASQVSDAIFYCGWHTCPLRPKSAPRRNIRQLVLLAV $*: * *: *: * * * * . * * * * * * * * * * * * * *:: * *: * * * * * * .$. . : $\star *:: *: * * *:$ :

AAAQRPIVMKAFNMLELTYGTFIQVVRGTYSVFALISAQNESLAQ 398 MQAQRPLVMKAFKMLELTYGTFLLVVRSTYSVFALFYAQTS---- 401
300

\section{0}

60

120

120

180

180

239

240

299

15

353

360

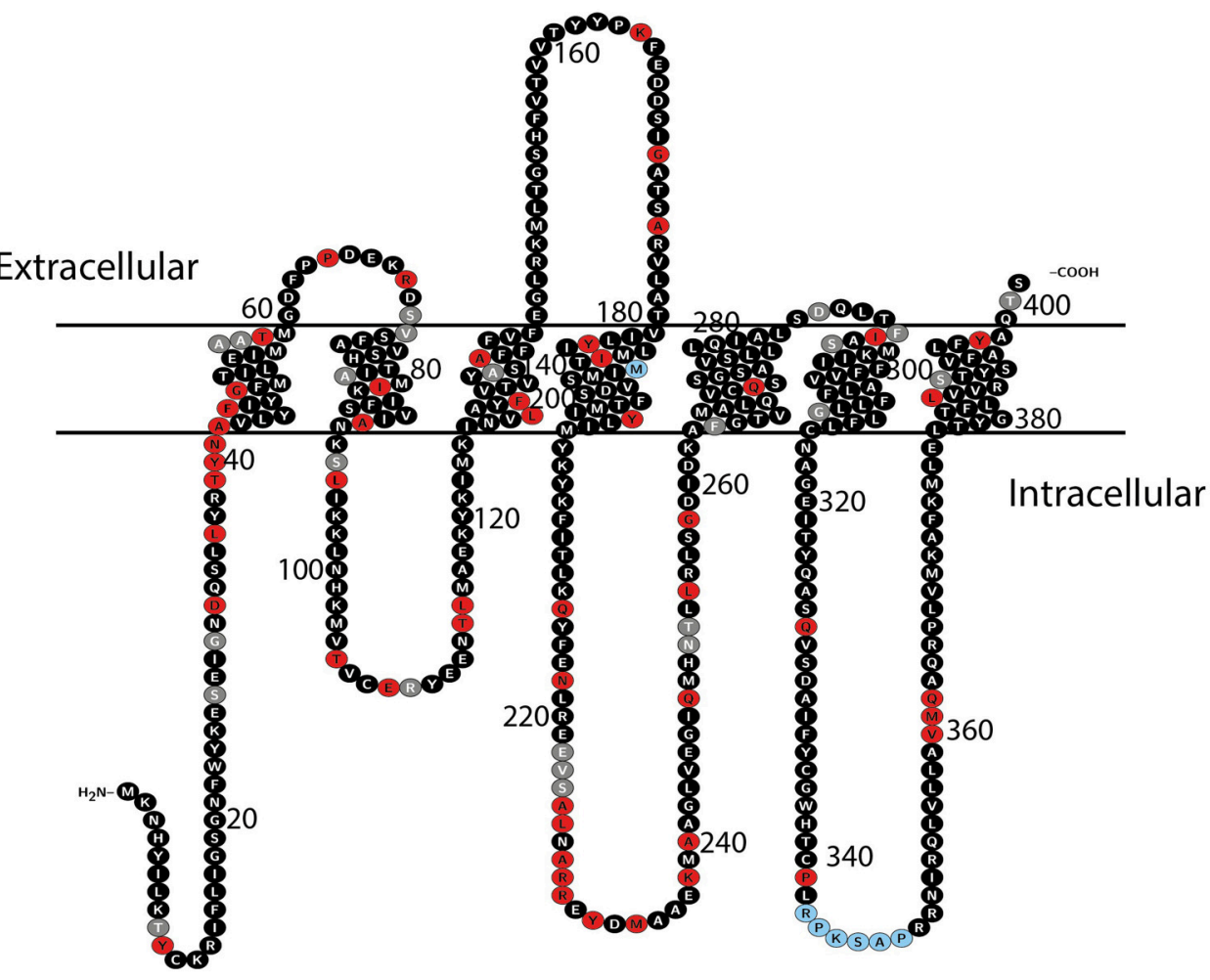

FIGURE 3 | (A) Amino acid alignment of CpomOR19 and SlitOR19. Amino acid sequence differences are indicated as highly (:) and moderately (.) conservative substitutions and non-conservative substitutions (blanks), while asterisks indicate identity across both sequences. (B) Putative protein topology of SlitOR19 and its differences with CpomOR19. Gray dots indicate moderately conservative substitutions, red dots indicate non-conservative substitution of residues and light blue dots indicate addition of residues in SlitOR19 as compared to CpomOR19.

a single mutation is enough to change the specificity of a sex pheromone receptor between two species of Ostrinia (Leary et al., 2012), demonstrating that minor changes in amino acid sequences can lead to conformational changes in membrane proteins that have profound effects on OR function, specificity and sensitivity (Curran and Engelman, 2003; Hopf et al., 2015).

For CpomOR19 and SlitOR19, most of the non-conserved mutations were found on the first transmembrane region 

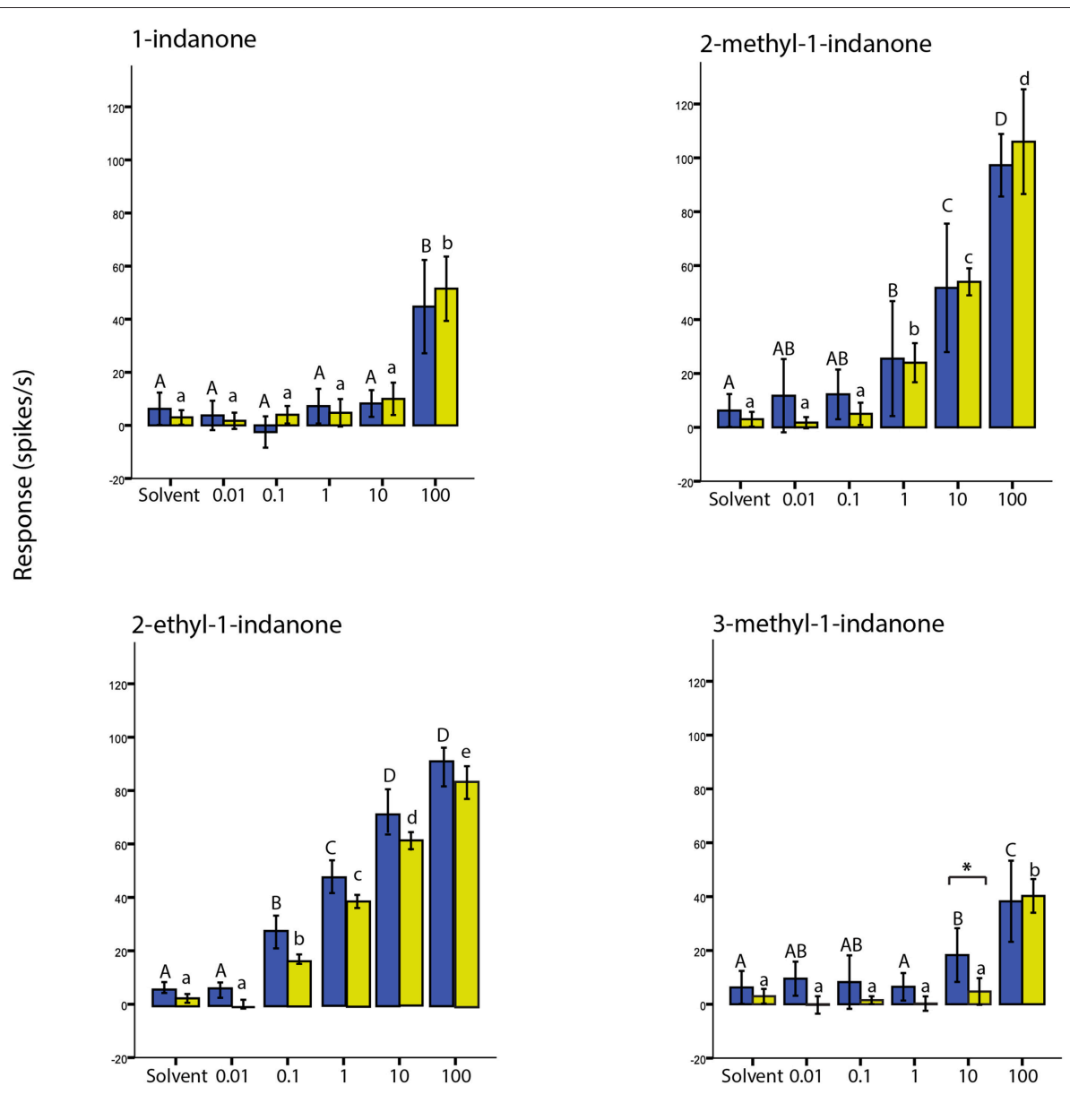

Dose $(\mu \mathrm{g})$

FIGURE 4 | Dose-dependent responses of CpomOR19 and SlitOR19 to 1-indanone and structurally related compounds. Responses to 2-ethyl-1-indanone are adjusted to account for differences in vapor pressure. Bars of the same color followed by different letters indicate subgroups with statistically significant differences. Asterisk denotes significant differences between species for the dose indicated at $P<0.01$ (Two-way ANOVA with repeated measures, LSD post-hoc test, $n=8$ ).

and on the intracellular loop 2 of the predicted proteins (Figure 3B). Hopf et al. (2015) showed that the N-terminus tail, the extracellular loop 2 and the intracellular loop 3, are kept under strong evolutionary constraint, indicating their functional importance in receptors of D. melanogaster. Point mutations within the third and sixth transmembrane regions can affect the sensitivity and selectivity of ORs, as demonstrated by Steinwender et al. (2015) for the pheromone receptor OR7 of Ctenopseustis oblicuana and Ctenopseustis herana, and may drive speciation events. In CpomOR19 and SlitOR19, these regions show only minor changes, except a deletion of the final four residues of the C-terminus sequence of SlitOR19. However, this deletion did not affect OR tuning, compared with CpomOR19. In contrast, Hill et al. (2015) recently demonstrated that a deletion of the C-terminus in one of the two paralogous ORs in the mosquito Culex quinquefasciatus has a profound effect on enantiomeric selectivity. The specific mechanisms governing OR functions remain, however, unknown. It therefore cannot not be excluded that non-conservative mutations concern even functional sites: amino acid interactions, which appear to strongly affect functional properties, may restore receptor tuning.

\section{CpomOR19 and SlitOR19 are Tuned to 1-Indanones}

Among the first panel of odorants 1-indanone elicited the strongest response (Table 1). Ensueing tests with a number of structurally related 1 -indanone analogs showed that the affinity of both ORs to 2-methyl-1-indanone and 2-ethyl-1-indanone was even higher (Figures 1, 4).

Analysis of the molecular receptive range of CpomOR19 and SlitOR19 provides insight into their interaction with odorant ligands. For both ORs, the nature and position of the functional group and the presence and position of methyl and ethyl substituents all affected receptor-ligand interactions. 
A carbonyl group in position 1 is required for biological activity, as demonstrated by the lack of response toward alcohols, hydrocarbons and an imine. This is in agreement with Liljefors et al. (1984), showing that the functional group plays an essential role in successful ligand-OR interactions. Acetophenone, a substance which interacts with the receptor through both the carbonyl group and the benzene ring at the same position in space as 1-indanone, did not elicit an OR response. We therefore deduce that the five-membered ring of the indane skeleton is required for biological activity. Finally, a complete lack of response to indan-1,2-dione indicates that the polarity and electron distribution of the additional keto-group intervene and prevent the molecule from binding to the OR. By introducing alkyl substituents as space-probes at different positions of the indane structure, we were able to characterize the degree of complementarity between this part of the substrate and the receptor. A similar approach was taken by Jönsson et al. (1992) to study the interaction of a moth sex pheromone with its receptor cell. Addition of a methyl and ethyl group to the second carbon of the five-membered ring increases the response. This suggests the alkyl group interacts with a complementary receptor site within the OR, that could consist of a hydrophobic "pocket." Our results also indicate that the addition of methyl space-probe groups to the benzene ring (4-, 5- and 6-methyl-1-indanone) decreased biological activity. We hypothesize that these additions caused repulsive, steric interference between the analog and a complementary receptor site of the OR.

Earlier analyses of the molecular receptive range of ORs by electrophysiological recordings from native olfactory sensory neurons (OSNs) support our findings. For example, Stranden et al. (2003) demonstrated structural-activity relationships in the electrophysiological responses of three heliothine moths to the sesquiterpene germacrene D. The selective response of these OSNs to germacrene $\mathrm{D}$ was defined by the ten-membered ring system, the position of three double bonds and the position of the isopropyl group. Research on pheromone receptors of the moth Agrotis segetum has also shown that changes in shape and bulkiness, length, position of the double bond or nature of the functional group of the (Z)-5-decenyl acetate molecule (one of the three pheromone components of this species), have an effect, direct or indirect, on the interaction of the molecules with the receptor binding sites. Here, the acetate group, the double bond and the terminal alkyl chain are the three molecular parts which are most likely responsible for the selectivity of the receptor (Bengtsson et al., 1987, 1990; Jönsson et al., 1991).

The response to the indanone analogs was overall similar for CpomOR19 and SlitOR19, although significant differences were observed in dose-response relationships to 3-methylindanone (Figure 4). This response shift may be due to residue substitutions. Further experiments, for example including ORs with induced point mutations, are required to reveal the basis of these differences.

\section{The Ecological Role of Indanes is Yet Unknown}

Semiochemicals are natural compounds which elicit a behavioral response, and which activate dedicated ORs at low concentrations (Bohbot and Dickens, 2012). Spodoptera larval frass, which deters oviposition in conspecific females, contains 1-indanone (Klein et al., 1990; Anderson et al., 1993), but we were unable to corroborate presence of 1 -indanone or any other indane in frass collections of S. littoralis reared on several diets (data not shown). Indanone is found in roots of tropical plants (Okpekon et al., 2009), decaying wood fungi (Rukachaisirikul et al., 2013), and filamentous marine cyanobacteria (Nagle et al., 2000), which are probably not relevant for S. littoralis or C. pomonella. However, our results indicate that one or several indanone analogs are ligands for CpomOR19 and SlitOR19, but the source of these compounds and their behavioral and ecological roles are yet to be elucidated.

Pterosins are a group of natural compounds, composed of modified 2-methyl-1-indanones (Syrchina and Semenov, 1982). Pterosins are produced by the fern Pteridium aquilinum and are known to be toxic and show anti-feeding effects in various insects (Jones and Firn, 1979). These compounds make good candidates for ligands of CpomOR19 and SlitOR19 since they are similar in structure to 2-methyl-1-indanone, which elicited one of the strongest responses in our screening. Unfortunately we were unable to test pterosins, because they are not commercially available and we did not screen plants producing them. To our knowledge, pterosins are not produced by other plants and ferns are not commonly found in C. pomonella and S. littoralis habitats, but structurally similar compounds may occur in their host or non-host plants. Further research on plant or insect chemical profiles, together with behavioral studies of substituted indanes, is needed to identify the natural, key ligands for OR19 and to decipher their ecological relevance.

The olfactory and behavioral responses of codling moth and cotton leafworm to host and non-host plants have been studied thoroughly (Bäckman et al., 2001; Bengtsson et al., 2001, 2014; Witzgall et al., 2005; Trona et al., 2010, 2013; Saveer et al., 2012; Binyameen et al., 2013, 2014; Borrero-Echeverry et al., 2015). Our study accentuates that analytical chemistry of current, known host plant associations provides an incomplete pool of compounds for the identification of the ligands mediating insect olfactory behavior. Our comparison of an ortholog OR in $C$. pomonella and $S$. littoralis validates functional characterization of OR repertoires as an alternative approach, leading to a more complete description of the olfactory system.

\section{ACKNOWLEDGMENTS}

This study was supported by the Linnaeus initiative "Insect Chemical Ecology, Ethology and Evolution (IC-E3)" (The Swedish Research Council Formas, SLU), by Formas (project number 2011 1370), and the Faculty of Landscape Architecture, Horticulture and Crop Production Science (SLU).

\section{SUPPLEMENTARY MATERIAL}

The Supplementary Material for this article can be found online at: http://journal.frontiersin.org/article/10.3389/fevo. 2015.00131

Supplementary Figure 1 | Response profile of CpomOR19 to synthetic compounds tested at $100 \mu \mathrm{g}$ on filter paper (mean $\pm \mathrm{SE}, n=5$ ). 


\section{REFERENCES}

Anderson, P., Hilker, M., Hansson, B., Bombosch, S., Klein, B., and Schildknecht, H. (1993). Oviposition deterring components in larval frass of Spodoptera littoralis (Boisd.) (Lepidoptera: Noctuidae): a behavioral and electrophysiological evaluation. J. Insect Physiol. 39, 129-137. doi: 10.1016/0022-1910(93)90104-Y

Andersson, M. N., Löfstedt, C., and Newcomb, R. D. (2015). Insect olfaction and the evolution of receptor tuning. Front. Ecol. Evol. 3:53. doi: $10.3389 /$ fevo.2015.00053

Arn, H., Guerin, P., Buser, H., Rauscher, S., and Mani, E. (1985). Sex pheromone blend of the codling moth, Cydia pomonella: evidence for a behavioral role of dodecan-1-ol. Experientia 41, 1482-1484. doi: 10.1007/BF01950048

Bäckman, A. C., Bengtsson, M., Borg-Karlsson, A. K., Liblikas, I., and Witzgall, P. (2001). Volatiles from apple eliciting antennal responses in female codling moth Cydia pomonella (L.) (Lepidoptera: Tortricidae): effect of plant injury and sampling technique. Z. Naturforsch. C 56, 262-268. doi: 10.1515/znc-20013-415

Bengtsson, J. M., Gonzalez, F., Cattaneo, A. M., Montagné, N., Walker, W. B., Bengtsson, M., et al. (2014). A predicted sex pheromone receptor of codling moth Cydia pomonella detects the plant volatile pear ester. Front. Ecol. Evol. 2:33. doi: $10.3389 /$ fevo.2014.00033

Bengtsson, J. M., Trona, F., Montagné, N., Anfora, G., Ignell, R., Witzgall, P., et al. (2012). Putative chemosensory receptors of the codling moth, Cydia pomonella, identified by antennal transcriptome analysis. PLoS ONE 7:e31620. doi: 10.1371/journal.pone.0031620

Bengtsson, M., Bäckman, A.-C., Liblikas, I., Ramirez, M. I., Borg-Karlson, A.K., Ansebo, L., et al. (2001). Plant odor analysis of apple: antennal response of codling moth females to apple volatiles during phenological development. J. Agric. Food Chem. 49, 3736-3741. doi: 10.1021/jf0100548

Bengtsson, M., Liljefors, T., and Hansson, B. S. (1987). Dienic analogs of (Z)-5decenyl acetate, a pheromone component of the turnip moth, Agrotis segetum: synthesis, conformational analysis and structure-activity relationships. Bioorg. Chem. 15, 409-422. doi: 10.1016/0045-2068(87)90036-8

Bengtsson, M., Liljefors, T., Hansson, B. S., Löfstedt, C., and Copaja, S. V. (1990). Structure-activity relationships for chain-shortened analogs of (Z)-5-decenyl acetate, a pheromone component of the turnip moth, Agrotis segetum. J. Chem. Ecol. 16, 667-684. doi: 10.1007/BF01016478

Bergstrom, L. G. W. (2008). Chemical communication by behavior-guiding olfactory signals. Chem. Commun. 34, 3959-3979. doi: 10.1039/b712681f

Binyameen, M., Hussain, A., Yousefi, F., Birgersson, G., and Schlyter, F. (2013). Modulation of reproductive behaviors by non-host volatiles in the polyphagous Egyptian cotton leafworm, Spodoptera littoralis. J. Chem. Ecol. 39, 1273-1283. doi: 10.1007/s10886-013-0354-4

Binyameen, M., Anderson, P., Ignell, R., Birgersson, G., Razaq, M., Shad, S. A., et al. (2014). Identification of plant semiochemicals and characterization of new olfactory sensory neuron types in a polyphagous pest moth, Spodoptera littoralis. Chem. Senses 39, 719-733. doi: 10.1093/chemse/bju046

Bischof, J., Maeda, R. K., Hediger, M., Karch, F., and Basler, K. (2007). An optimized transgenesis system for Drosophila using germ-line-specific بC31 integrases. Proc. Natl. Acad. Sci. U.S.A. 104, 3312-3317. doi: 10.1073/pnas.0611511104

Bohbot, J. D., and Dickens, J. C. (2012). Selectivity of odorant receptors in insects. Front. Cell. Neurosci. 6:29. doi: 10.3389/fncel.2012.00029

Bohbot, J. D., Jones, P. L., Wang, G., Pitts, R. J., Pask, G. M., and Zwiebel, L. J. (2011). Conservation of indole responsive odorant receptors in mosquitoes reveals an ancient olfactory trait. Chem. Senses 36, 149-160. doi: 10.1093/chemse/bjq105

Bohbot, J., Pitts, R. J., Kwon, H. W., Rutzler, M., Robertson, H. M., and Zwiebel, L. J. (2007). Molecular characterization of the Aedes aegypti odorant receptor gene family. Insect Mol. Biol. 16, 525-537. doi: 10.1111/j.1365-2583.2007. 00748.x

Borrero-Echeverry, F., Becher, P. G., Birgersson, G. Å. O., Bengtsson, M., Witzgall, P., and Saveer, A. M. (2015). Flight attraction of Spodoptera littoralis (Lepidoptera, Noctuidae) to cotton headspace and synthetic volatile blends. Front. Ecol. Evol. 3:56. doi: 10.3389/fevo.2015.00056

Bradley, J. D., Tremewan, W. G., and Smith, A. (1979). British Tortricoid Moths. Tortricidae: Olethreutinae. London: The Ray Society.
Brigaud, I., Montagné, N., Monsempes, C., François, M. C., and Jacquin-Joly, E. (2009). Identification of an atypical insect olfactory receptor subtype highly conserved within noctuids. FEBS J. 276, 6537-6547. doi: 10.1111/j.17424658.2009.07351.x

Cao, D., Liu, Y., Wei, J., Liao, X., Walker, W. B., Li, J., et al. (2014). Identification of candidate olfactory genes in Chilo suppressalis by antennal transcriptome analysis. Int. J. Biol. Sci. 10, 846-860. doi: 10.7150/ijbs.9297

Carey, A. F., Wang, G., Su, C. Y., Zwiebel, L. J., and Carlson, J. R. (2010). Odorant reception in the malaria mosquito Anopheles gambiae. Nature 464, 66-71. doi: 10.1038 /nature 08834

Corcoran, J. A., Jordan, M. D., Thrimawithana, A. H., Crowhurst, R. N., and Newcomb, R. D. (2015). The peripheral olfactory repertoire of the lightbrown apple moth, Epiphyas postvittana. PLoS ONE 10:e0128596. doi: 10.1371/journal.pone.0128596

Curran, A. R., and Engelman, D. M. (2003). Sequence motifs, polar interactions and conformational changes in helical membrane proteins. Curr. Opin. Struct. Biol. 13, 412-417. doi: 10.1016/S0959-440X(03)00102-7

de Fouchier, A., Mirabeau, O., Montagné, N., and Jacquin-Joly, E. (2014). "Current views on the function and evolution of lepidopteran olfactory receptors," in Short Views on Insect Biochemistry and Molecular Biology, Chap. 17, Vols. 1, 2, eds R. Chandrasekar, B. K. Tyagi, Z. Z. Gui, and G. R. Reeck (Manhattan, NY: International Book Mission; Academic Publisher), 385-408.

Depetris-Chauvin, A., Galagovsky, D., and Grosjean, Y. (2015). Chemicals and chemoreceptors: ecologically relevant signals driving behavior in Drosophila. Front. Ecol. Evol. 3:41. doi: 10.3389/fevo.2015.00041

Dobritsa, A. A., van der Goes van Naters, W., Warr, C. G., Steinbrecht, R. A., and Carlson, J. R. (2003). Integrating the molecular and cellular basis of odor coding in the Drosophila antenna. Neuron 37, 827-841. doi: 10.1016/S08966273(03)00094-1

Engsontia, P., Sangket, U., Chotigeat, W., and Satasook, C. (2014). Molecular evolution of the odorant and gustatory receptor genes in lepidopteran insects: implications for their adaptation and speciation. J. Mol. Evol. 79, 21-39. doi: 10.1007/s00239-014-9633-0

Grosse-Wilde, E., Kuebler, L. S., Bucks, S., Vogel, H., Wicher, D., and Hansson, B. S. (2011). Antennal transcriptome of Manduca sexta. Proc. Natl. Acad. Sci. U.S.A. 108, 7449-7454. doi: 10.1073/pnas.1017963108

Gu, S. H., Sun, L., Yang, R. N., Wu, K. M., Guo, Y. Y., Li, X. C., et al. (2014). Molecular characterization and differential expression of olfactory genes in the antennae of the black cutworm moth Agrotis ipsilon. PLoS ONE 9:e103420. doi: 10.1371/journal.pone.0103420

Hallem, E. A., Ho, M. G., and Carlson, J. R. (2004). The molecular basis of odor coding in the Drosophila antenna. Cell 117, 965-979. doi: 10.1016/j.cell.2004.05.012

Hansson, B. S., and Stensmyr, M. C. (2011). Evolution of insect olfaction. Neuron 72, 698-711. doi: 10.1016/j.neuron.2011.11.003

Hill, C. A., Fox, A. N., Pitts, R. J., Kent, L. B., Tan, P. L., Chrystal, M. A., et al. (2002).G protein-coupled receptors in Anopheles gambiae. Science 298, 176-178. doi: 10.1126/science.1076196

Hill, S. R., Majeed, S., and Ignell, R. (2015). Molecular basis for odorant receptor tuning: a short C-terminal sequence is necessary and sufficient for selectivity of mosquito Or8. Insect Mol. Biol. 24, 491-501. doi: 10.1111/imb. 12176

Hopf, T. A., Morinaga, S., Ihara, S., Touhara, K., Marks, D. S., and Benton, R. (2015). Amino acid coevolution reveals three-dimensional structure and functional domains of insect odorant receptors. Nat. Commun. 6:6077. doi: $10.1038 /$ ncomms 7077

Jacquin-Joly, E., Legeai, F., Montagné, N., Monsempes, C., François, M.-C., Poulain, J., et al. (2012). Candidate chemosensory genes in female antennae of the noctuid moth Spodoptera littoralis. Int. J. Biol. Sci. 8, 1036. doi: 10.7150/ijbs.4469

Jacquin-Joly, E., and Merlin, C. (2004). Insect olfactory receptors: contributions of molecular biology to chemical ecology. J. Chem. Ecol. 30, 2359-2397. doi: 10.1007/s10886-004-7941-3

Jiang, X.-J., Guo, H., Di, C., Yu, S., Zhu, L., Huang, L.-Q., et al. (2014). Sequence similarity and functional comparisons of pheromone receptor orthologs in two closely related Helicoverpa species. Insect Biochem. Mol. Biol. 48, 63-74. doi: 10.1016/j.ibmb.2014.02.010 
Jones, C. G., and Firn, R. D. (1979). Resistance of Pteridium aquilinum to attack by non-adapted phytophagous insects. Biochem. Syst. Ecol. 7, 95-101. doi: 10.1016/0305-1978(79)90015-2

Jones, P. L., Pask, G. M., Rinker, D. C., and Zwiebel, L. J. (2011). Functional agonism of insect odorant receptor ion channels. Proc. Natl. Acad. Sci. U.S.A. 108, 8821-8825. doi: 10.1073/pnas.1102425108

Jönsson, S., Liljefors, T., and Hansson, B. S. (1991). Alkyl substitution in terminal chain of (Z)-5-decenyl acetate, a pheromone component of turnip moth, Agrotis segetum. Synthesis, single-sensillum recordings, and structureactivity relationships. J. Chem. Ecol. 17, 103-122. doi: 10.1007/BF009 94425

Jönsson, S., Liljefors, T., and Hansson, B. S. (1992). Introduction of methyl groups to acetate substituted chain of (Z)-5-decenyl acetate, a pheromone component of turnip moth, Agrotis segetum. Synthesis, single-sensillum recordings, and structure-activity relationships. J. Chem. Ecol. 18, 637-657. doi: 10.1007/BF00987825

Jordan, M. D., Anderson, A., Begum, D., Carraher, C., Authier, A., Marshall, S. D., et al. (2009). Odorant receptors from the light brown apple moth (Epiphyas postvittana) recognize important volatile compounds produced by plants. Chem. Senses 34, 383-394. doi: 10.1093/chemse/bjp010

Karner, T., Schneider, I., Schultze, A., Breer, H., and Krieger, J. (2015). Coexpression of six tightly clustered odorant receptor genes in the antenna of the malaria mosquito Anopheles gambiae. Front. Ecol. Evol. 3:26. doi: 10.3389/fevo.2015.00026

Klein, B., Schildknecht, H., Hilker, M., and Bombosch, S. (1990). Eiablagehemmende wirkstoffe aus dem Larvenkot von Spodoptera littoralis (Boisd.). Z. Naturforsch. 45, 895-901.

Krieger, J., Klink, O., Mohl, C., Raming, K., and Breer, H. (2003). A candidate olfactory receptor subtype highly conserved across different insect orders. J. Comp. Physiol. A 189, 519-526. doi: 10.1007/s00359-0030427-x

Kristensen, N. P., Scoble, M. J., and Karsholt, O. (2007). Lepidoptera phylogeny and systematics: the state of inventorying moth and butterfly diversity. Zootaxa $1668,699-747$

Larsson, M. C., Domingos, A. I., Jones, W. D., Chiappe, M. E., Amrein, H., and Vosshall, L. B. (2004). Or83b encodes a broadly expressed odorant receptor essential for Drosophila olfaction. Neuron 43, 703-714. doi: 10.1016/j.neuron.2004.08.019

Leary, G. P., Allen, J. E., Bunger, P. L., Luginbill, J. B., Linn, C. E. Jr, Macallister, I. E., et al. (2012). Single mutation to a sex pheromone receptor provides adaptive specificity between closely related moth species. Proc. Natl. Acad. Sci. U.S.A. 109, 14081-14086. doi: 10.1073/pnas.1204661109

Legeai, F., Malpel, S., Montagné, N., Monsempes, C., Cousserans, F., Merlin, C., et al. (2011). An expressed sequence tag collection from the male antennae of the noctuid moth Spodoptera littoralis: a resource for olfactory and pheromone detection research. BMC Genomics 12:86. doi: 10.1186/1471-216412-86

Liljefors, T., Thelin, B., and Van Der Pers, J. N. C. (1984). Structure activity relationships between stimulus molecule and response of a pheromone receptor cell in turnip moth, Agrotis segetum - modification of the acetate group. J. Chem. Ecol. 10, 1661-1675. doi: 10.1007/BF00987353

Liu, N. Y., Xu, W., Papanicolaou, A., Dong, S. L., and Anderson, A. (2014). Identification and characterization of three chemosensory receptor families in the cotton bollworm Helicoverpa armigera. BMC Genomics 15:597. doi: 10.1186/1471-2164-15-597

Martin, J. P., Beyerlein, A., Dacks, A. M., Reisenman, C. E., Riffell, J. A., Lei, H., et al. (2011). The neurobiology of insect olfaction: sensory processing in a comparative context. Progr. Neurobiol. 95, 427-447. doi: 10.1016/j.pneurobio.2011.09.007

Montagné, N., Chertemps, T., Brigaud, I., François, A., François, M. C., de Fouchier, A., et al. (2012). Functional characterization of a sex pheromone receptor in the pest moth Spodoptera littoralis by heterologous expression in Drosophila. Eur. J. Neurosci. 36, 2588-2596. doi: 10.1111/j.14609568.2012.08183.x

Montagné, N., de Fouchier, A., Newcomb, R. D., and Jacquin-Joly, E. (2014). Advances in the identification and characterization of olfactory receptors in insects. Prog. Mol. Biol. Transl. Sci. 130, 55-80. doi: 10.1016/bs.pmbts.2014.11.003
Nagle, D. G., Zhou, Y.-D., Park, P. U., Paul, V. J., Rajbhandari, I., Duncan, C. J., et al. (2000). A new indanone from the marine cyanobacterium Lyngbya majuscula that inhibits hypoxia-induced activation of the VEGF promoter in Hep3B cells. J. Nat. Prod. 63, 1431-1433. doi: 10.1021/np000216e

Okpekon, T., Millot, M., Champy, P., Gleye, C., Yolou, S., Bories, C., et al. (2009). A novel 1-indanone isolated from Uvaria afzelii roots. Nat. Prod. Res. 23, 909-915. doi: 10.1080/14786410802497240

Omasits, U., Ahrens, C. H., Müller, S., and Wollscheid, B. (2014). Protter: interactive protein feature visualization and integration with experimental proteomic data. Bioinformatics 30, 884-886. doi: 10.1093/bioinformatics/ btt607

Poivet, E., Gallot, A., Montagné, N., Glaser, N., Legeai, F., and Jacquin-Joly, E. (2013). A comparison of the olfactory gene repertoires of adults and larvae in the noctuid moth Spodoptera littoralis. PLoS ONE 8:e60263. doi: 10.1371/journal.pone.0060263

Rukachaisirikul, V., Buadam, S., Sukpondma, Y., Phongpaichit, S., Sakayaroj, J., and Hutadilok-Towatana, N. (2013). Indanone and mellein derivatives from the Garcinia-derived fungus Xylaria sp. PSU-G12. Phytochem. Lett. 6, 135-138. doi: 10.1016/j.phytol.2012.11.007

Rützler, M., and Zwiebel, L. (2005). Molecular biology of insect olfaction: recent progress and conceptual models. J. Comp. Physiol. A 191, 777-790. doi: 10.1007/s00359-005-0044-y

Salama, H. S., Dimetry, N. Z., and Salem, S. A. (1971). On the host preference and biology of the cotton leaf worm Spodoptera littoralis Bois. J. Appl. Entomol. 67, 261-266. doi: 10.1111/j.1439-0418.1971.tb02122.x

Sánchez-Gracia, A., Vieira, F. G., and Rozas, J. (2009). Molecular evolution of the major chemosensory gene families in insects. Heredity 103, 208-216. doi: 10.1038/hdy.2009.55

Saveer, A. M., Kromann, S., Birgerson, G., Bengtsson, M., Lindblom, T., Balkenius, A., et al. (2012). Floral to green: mating switches moth olfactory coding and preference. Proc. Biol. Sci. 279, 2314-2322. doi: 10.1098/rspb.2011.2710

Smadja, C., and Butlin, R. K. (2009). On the scent of speciation: the chemosensory system and its role in premating isolation. Heredity 102, 77-97. doi: 10.1038/hdy.2008.55

Steinwender, B., Thrimawithana, A. H., Crowhurst, R. N., and Newcomb, R. D. (2015). Pheromone receptor evolution in the cryptic leafroller species, Ctenopseustis obliquana and C. herana. J. Mol. Evol. 80, 42-56. doi: 10.1007/s00239-014-9650-z

Stensmyr, M. C., Dekker, T., and Hansson, B. S. (2003). Evolution of the olfactory code in the Drosophila melanogaster subgroup. Proc. R. Soc. B 270, 2333-2340. doi: 10.1098/rspb.2003.2512

Stranden, M., Liblikas, I., König, W., Almaas, T., Borg-Karlson, A.-K., and Mustaparta, H. (2003). (-)-Germacrene D receptor neurones in three species of heliothine moths: structure-activity relationships. J. Comp. Physiol. A 189, 563-577. doi: 10.1007/s00359-003-0434-y

Su, C. Y., Menuz, K., and Carlson, J. R. (2009). Olfactory perception: receptors, cells, and circuits. Cell 139, 45-59. doi: 10.1016/j.cell.2009.09.015

Suh, E., Bohbot, J., and Zwiebel, L. J. (2014). Peripheral olfactory signaling in insects. Curr. Opin. Insect Sci. 6, 86-92. doi: 10.1016/j.cois.2014.10.006

Syrchina, A., and Semenov, A. (1982). Natural indanones. Chem. Nat. Comp. 18, 1-11. doi: 10.1007/BF00581584

Tamura, K., Stecher, G., Peterson, D., Filipski, A., and Kumar, S. (2013). MEGA6: molecular evolutionary genetics analysis version 6.0. Mol. Biol. Evol. 30, 2725-2729. doi: 10.1093/molbev/mst197

Trona, F., Anfora, G., Balkenius, A., Bengtsson, M., Tasin, M., Knight, A., et al. (2013). Neural coding merges sex and habitat chemosensory signals in an insect herbivore. Proc. R. Soc. B 280:20130267. doi: 10.1098/rspb. 2013.0267

Trona, F., Anfora, G., Bengtsson, M., Witzgall, P., and Ignell, R. (2010). Coding and interaction of sex pheromone and plant volatile signals in the antennal lobe of the codling moth Cydia pomonella. J. Exp. Biol. 213, 4291-4303. doi: 10.1242/jeb.047365

Witzgall, P., Ansebo, L., Yang, Z., Angeli, G., Sauphanor, B., and Bengtsson, M. (2005). Plant volatiles affect oviposition by codling moths. Chemoecology 15, 77-83. doi: 10.1007/s00049-005-0295-7

Witzgall, P., Proffit, M., Rozpedowska, E., Becher, P. G., Andreadis, S., Coracini, M., et al. (2012). "This is not an apple" - yeast mutualism in codling moth. J. Chem. Ecol. 38, 949-957. doi: 10.1007/s10886-012-0158-y 
Yang, B., Ozaki, K., Ishikawa, Y., and Matsuo, T. (2015). Identification of candidate odorant receptors in asian corn borer Ostrinia furnacalis. PLoS ONE 10:e0121261. doi: 10.1371/journal.pone.0121261

Zhang, J., Wang, B., Dong, S. L., Cao, D. P., Dong, J. F., Walker, W. B., et al. (2015a). Antennal transcriptome analysis and comparison of chemosensory gene families in two closely related noctuid moths, Helicoverpa armigera and H. assulta. PLoS ONE 10:e0117054. doi: 10.1371/journal.pone.0117054

Zhang, J., Yan, S., Liu, Y., Jacquin-Joly, E., Dong, S., and Wang, G. (2015b). Identification and functional characterization of sex pheromone receptors in the common cutworm (Spodoptera litura). Chem. Senses 40, 7-16. doi: 10.1093/chemse/bju052
Conflict of Interest Statement: The authors declare that the research was conducted in the absence of any commercial or financial relationships that could be construed as a potential conflict of interest.

Copyright (c) 2015 Gonzalez, Bengtsson, Walker, Sousa, Cattaneo, Montagné, de Fouchier, Anfora, Jacquin-Joly, Witzgall, Ignell and Bengtsson. This is an open-access article distributed under the terms of the Creative Commons Attribution License (CC $B Y)$. The use, distribution or reproduction in other forums is permitted, provided the original author(s) or licensor are credited and that the original publication in this journal is cited, in accordance with accepted academic practice. No use, distribution or reproduction is permitted which does not comply with these terms. 